\title{
O BAIRRO ÁGUA MINERAL NO CONTEXTO DA EXPANSÃO DA CIDADE DE TERESINA, PIAUÍ
}

\author{
Caroline da Silva Mateus ${ }^{(a)}$, Iracilde Maria de Moura Fé Lima ${ }^{(b)}$ \\ (a)Graduanda em Geografia, Universidade Federal do Piauí, karol_mateus@ hotmail.com \\ (b) $\operatorname{Prof}^{\mathrm{a}} \mathrm{Dr}^{\mathrm{a}}$ da Universidade Federal do Piauí, iracildefelima@ufpi.edu.br
}

Eixo: Uso e ocupação das terras e legislação ambiental

\begin{abstract}
Resumo
O presente trabalho teve como objetivo estudar o bairro Água Mineral como parte do processo de expansão da cidade de Teresina, capital do Piauí, Brasil. Esse bairro se instalou em terrenos de encostas íngremes se expandindo para os terraços fluviais do rio Poti, ocupando assim parte da área de uma APP na zona norte da cidade, na década de 1970. A partir de então a cidade se expandiu além dos limites do sítio urbano projetado para a instalação inicial da cidade, em 1852. Os procedimentos metodológicos adotados consistiram em revisão bibliográfica e pesquisa de campo, incluindo entrevistas a antigos moradores. Identificou-se que o bairro surgiu a partir de ocupações habitacionais irregulares, passando a conviver com problemas socioambientais principalmente em períodos de enchentes excepcionais do rio Poti. No entanto, com o crescimento da cidade, deixou de ser um bairro periférico, dispondo atualmente de uma razoável infraestrutura de serviços públicos e privados.
\end{abstract}

Palavras chave: Crescimento urbano; Problemas socioambientais; Terraço do rio Poti; Área de Proteção Ambiental.

\section{Introdução}

O meio ambiente é social e historicamente construído em função da interação de uma sociedade em movimento com um espaço físico que se modifica (MORIN, 1998). Essa relação, segundo Santos (1994), molda um ambiente retratando a diversidade das classes, rendas e modelos culturais. Nesses tipos de espaços geralmente passa a ocorrer uma interferência humana na natureza de forma inadequada gerando problemas socioambientais negativos (GUERRA; MARÇAL, 2006).

A cidade de Teresina, localizada no Estado do Piauí, mesmo sendo uma das primeiras cidades brasileiras planejada para sediar a capital (ABREU; LIMA, 2000), não manteve ações de planejamento para acompanhar sua expansão. Isto fez gerar formas de ocupação da terra irregulares, muitas vezes em áreas de riscos à ocorrência de problemas socioambientais. Dentre essas áreas encontram-se os terraços inundáveis por ocasião de cheias excepcionais do rio Poti (LIMA, 2011) que se constitui uma Área de Proteção Permanente (CÓDIGO FLORESTAL, 2012), onde se instalou parte do bairro Água Mineral. 
Os procedimentos metodológicos adotados envolveram inicialmente o levantamento e análise do referencial teórico e documental sobre o tema e sobre a cidade. Após esse estudo foram realizados trabalhos de observação de campo, complementadas com entrevistas não estruturadas a antigos moradores do bairro, seguidos da organização final do trabalho.

Os resultados permitiram concluir-se que, mesmo enfrentando problemas socioambientais como inundações periódicas do rio Poti, a localização do bairro deixou de ser caracterizada como favela, como condição de periferia urbana desassistida. Isto porque a cidade se expandiu para muito além dos limites desse bairro, dotando a Zona Centro Norte de Teresina, onde ele se inclui, de serviços básicos públicos para atendimento à sua população, tendo destaque uma avenida que possibilita suas relações a muitos bairros e um grande Parque Ambiental.

\section{Resultados e discursões}

A expansão da cidade de Teresina ultrapassou o espaço delimitado para seu sítio inicial a partir da década de 1960, ocupando espaços nas direções sul, leste e norte, de forma descontínua. A sua população que era de apenas 21.692 habitantes em 1872, aumentou para 144.799 pessoas em 1960 e para 230.168 em 1970 (IBGE, 2010).

A partir de então, o crescimento da área urbana de Teresina foi incorporando chácaras e fazendas do seu entorno, ocupando as margens das estradas e dos rios Poti e Parnaíba, fazendo multiplicarem-se as ruas e avenidas. Estas se formaram desconsiderando o traçado inicial da cidade, o de tabuleiro de xadrez, crescendo a ocupação nos terraços fluviais desses dois rios e também em morros residuais (LIMA, 2002).

Com esse intenso crescimento da cidade, a visão elitista de (re) organizar o espaço fazia com que os pobres, à medida que iam construindo novos prédios públicos e particulares para as elites, fossem aos poucos afastados para a periferia urbana. Essa prática se associou aos movimentos de imigração desencadeados a partir da década de 1950, contribuindo para que se iniciasse o processo de favelização no entorno do centro de Teresina (ARAÚJO; NASCIMENTO, 2012).

O bairro Água Mineral se constitui um dos bairros que nasceu no bojo dessa dinâmica de expansão espacial e condições socioeconômicas. Ao atrair cada vez mais famílias para ocuparem o espaço do entorno de uma fonte de água mineral, por isto ficou conhecido por este nome (PMT, 2014), foi se instalando de forma desordenada em áreas de morros e de uma faixa dos terraços fluviais do rio Poti, locais sem a menor estrutura para abrigar tantas famílias (Figura 1). As casas eram construídas muito próximas umas das outras, 


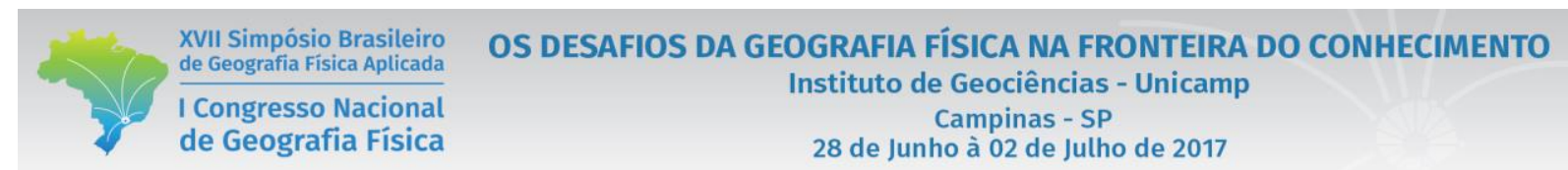

geralmente cobertas de palha, sem arruamento organizado nem serviços de agua e de energia elétrica, conforme destacam antigos moradores desse bairro.

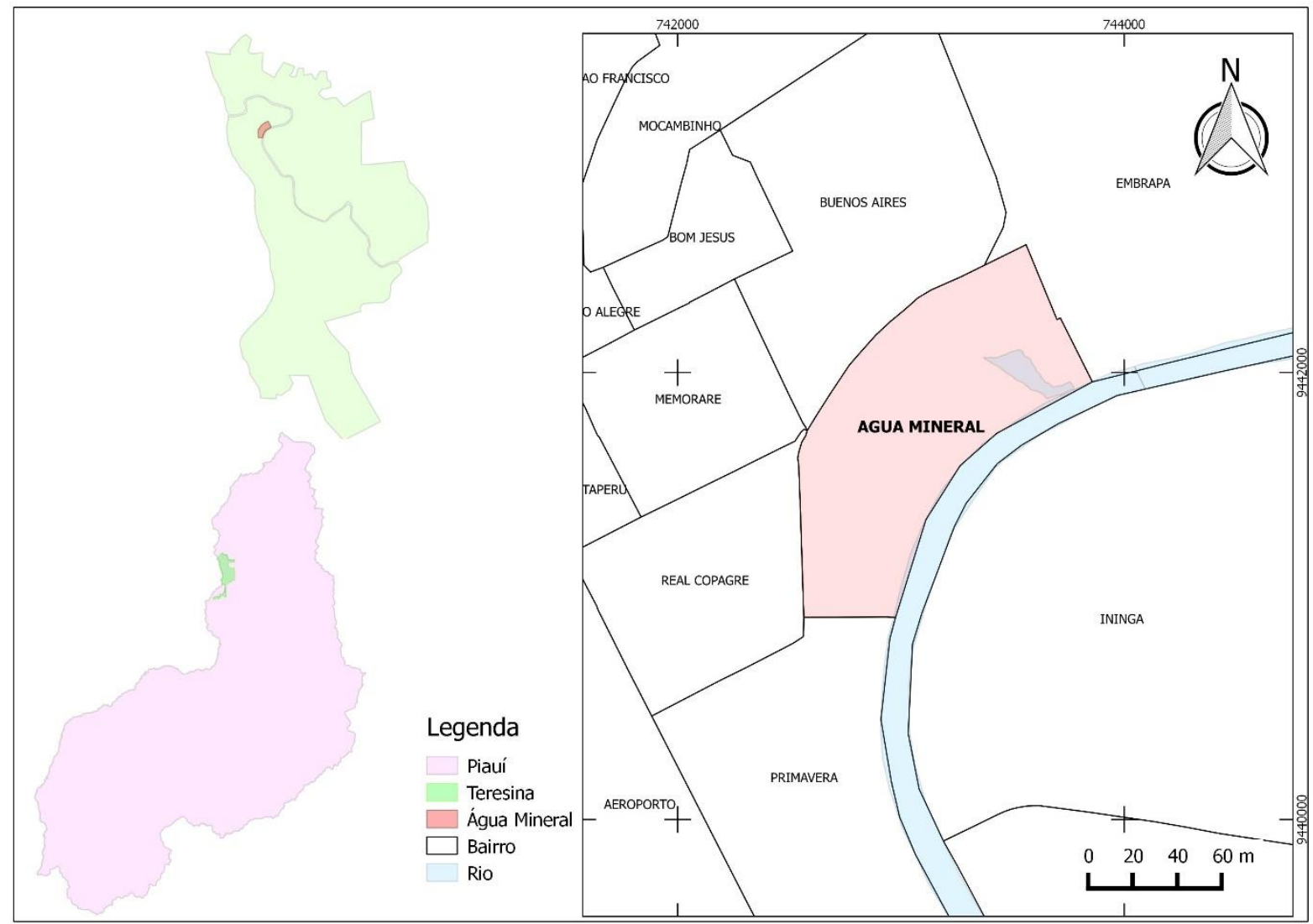

Figura 1 - Mapa de localização do bairro Água Mineral na cidade de Teresina Fonte: Google Earth (imagem dia 17/9/2015). Org. Allan Antunes da S. Mateus (2017).

Como este, vários bairros da cidade também não respeitaram as Áreas de Proteção Permanente (APP) ocupando estas e outras áreas consideradas locais de riscos de inundação dos rios regionais Parnaíba e Poti e das lagoas fluviais (CHAVES, 2015). Essas ocupações ocorreram por invasões de propriedades privadas, por iniciativa de loteamentos de agentes imobiliários particulares, como também por agentes públicos, principalmente através de programas habitacionais federais (FAÇANHA, 2003).

Ao se observar a evolução de Teresina e do Bairro Água Mineral, pode-se perceber que houve um significativo crescimento da cidade, enquanto o crescimento da população desse bairro entre 1991 e 2010 teve um decréscimo de 1,4\%. Esse crescimento negativo se explica, possivelmente, porque parte de sua população saiu deste para residir em outros bairros da cidade, informação esta que ainda carece de investigação. A participação da população do bairro em relação ao total da cidade, corresponde a 1,58\% dos habitantes, tendo apresentado uma posição de destaque em termos de contingente populacional: a $16^{\mathrm{a}}$. em relação aos 112 bairros existentes na cidade (IBGE, 2010). 
Com a evolução mais recente da cidade, ampliou-se o seu sítio urbano com a instalação de novos bairros na Zona Norte, para além do bairro Agua Mineral. Acompanhado da ampliação da instalação de serviços públicos, como a construção/pavimentação de vias de acesso, abastecimento de água, energia elétrica, esgotamento sanitário e coleta de lixo, este bairro deixou de pertencer à condição de periferia e favela urbana (Figura 2). Também foi sendo contemplado com outros serviços de educação (escolas e creches), posto médico, posto policial, praças e áreas de lazer, pois sua área é delimitada por um grande Parque Ambiental e uma grande avenida por onde circulam transportes públicos.

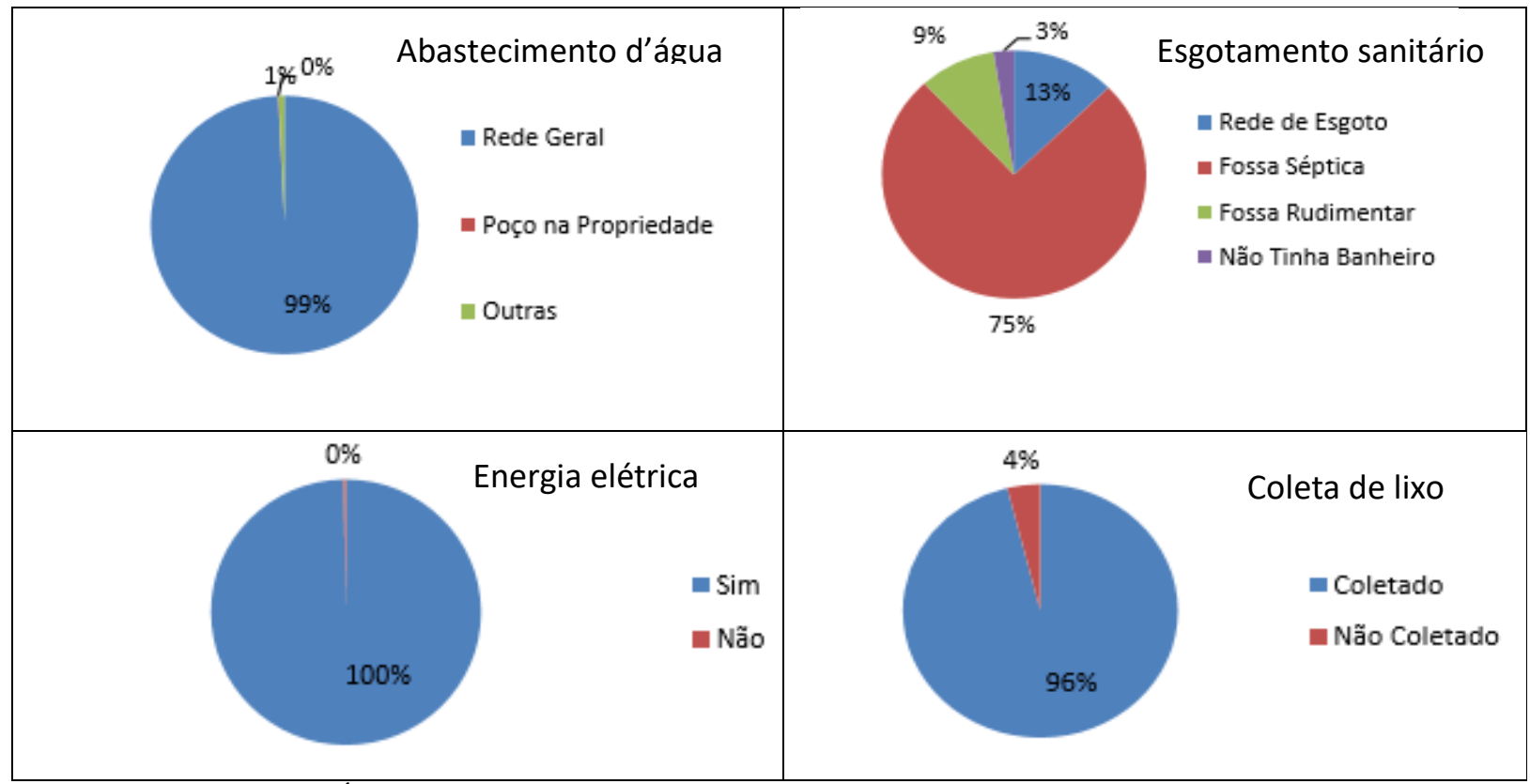

Figura 2 - Bairro Água Mineral: número de domicílios atendidos por tipo de serviço básico, em 2010 Fonte: PMT (2016).

Assim, a ocupação dessa área que em princípio ocorria motivada, dentre outros fatores, pelo baixo custo da terra em função da deficiência de infra-estrutura básica e por estarem sujeitas a inundações, não sendo por algum tempo visada pelo capital e tornando-se uma das áreas propícias para a ocupação da população de baixa renda (VIEIRA et al, 2007), mais recentemente evoluiu para melhores condições de vida dos seus moradores.

\section{Conclusão}

O bairro Água Mineral teve origem a partir da invasão de grupos de famílias de baixa renda em terras consideradas de risco para ocupação residencial, na década de 1970. Como ocorreu também nas zonas sul e leste, o surgimento deste bairro se somou aos demais, extrapolando o limite norte do sítio urbano projetado para a fundação da cidade em 1852. Foi a partir de então que o sítio urbano de Teresina perdeu 
definitivamente o formato original de tabuleiro de xadrez, no bojo do processo de seu crescimento desordenado.

Porém, se por um lado as formas de relevo ocupadas ainda hoje lhe proporcionam problemas socioambientais decorrentes principalmente das enchentes periódicas do rio Poti na área de terraços inundáveis e da irregularidade do traçado das ruas nas encostas íngremes do relevo local; por outro lado deixou a condição de periferia da cidade, totalmente desassistida. Assim, nas últimas décadas passou a contar com uma razoável infraestrutura de serviços e com uma certa valorização imobiliária, também por estar localizado ao lado de uma movimentada avenida e de uma grande reserva de vegetação nativa: o Parque da Cidade.

\section{Bibliografia}

ABREU, I. G.; LIMA, I. M. M. F. Igreja do Amparo: O Marco Zero de Teresina. In: Revista Cadernos de Teresina. Teresina-PI: Fundação Monsenhor Chaves, p.15-20, 2000.

BRASIL. Congresso Nacional. Código Florestal. Lei n 12.651 de 25 de maio de 2012.

CHAVES, S. V. V. Vulnerabilidade às inundações em Teresina, Piauí. Tese (Doutorado). 231f. Programa de PósGraduação em Geografia. Universidade Estadual Paulista "Júlio de Mesquita Filho". Rio Claro (SP), 2015.

FAÇANHA, A. C. A evolução urbana de Teresina: passado, presente e .... Carta CEPRO. Teresina: CEPRO, v.22, n.1, jan/jun. 2003, p.59-69.

GUERRA; A. J. T.; MARÇAL, M. S. Geomorfologia Ambiental. Rio de janeiro: Bertrand do Brasil, 2006.

LIMA, I. M. M. F. Teresina: Urbanização e Meio Ambeinte. In: Scientia et Spes. Teresina: Instituto Camilo Filho, v.1, n. 2, 2002, p. 181-206. Disponível em: http://iracildefelima.webnode.com.

O relevo de Teresina, PI: compartimentação e dinâmica atual. IX ENANPEGE - Encontro Nacional da Associação Nacional de Pós-Graduação e Pesquisa em Geografia. Goiânia, 2011. Disponível em: http://iracildefelima.webnode.com.

SANTOS, Milton. Técnica, Espaço, Tempo - Globalização e meio técnico-científico informacional. São Paulo. 38pp, 1994.

VIEIRA, D. M.; TEIXEIRA, P. W. G. N.; LOPES, W. G. R. Identificação dos usos e ocupações do solo nas áreas de preservação permanente do rio Poti e sua compatibilidade legal no perímetro urbano de Teresina, PiauíBrasil. In: VII Encontro da Sociedade Brasileira de Economia Ecológica. Fortaleza, 2007

PMT - Prefeitura Municipal de Teresina. Dinâmica populacional. Teresina: PMT, 2014. Disponível em: http://semplan.teresina.pi.gov.br/wp-content/uploads/2014/09/TERESINA-POPULA\%C3\%87\%C3\%83O.pdf. Acesso em: 10 jan.2017.

Teresina - Perfil dos bairros - Regional SDU Centro Norte bairro Água Mineral. Disponível em: http://semplan.teresina.pi.gov.br/wp-content/uploads/2016/08/ÁGUA-MINERAL-20161.pdf. Acesso em 10 jan.2017.

ARAÚJO, K. S. F.; NASCIMENTO, F. A. A capital do Piauí na década de 1970: Teresina sonhada, construída e vivida pelos pobres urbanos. In: VI Simpósio Nacional de História Cultural. Anais... Teresina: UFPI, 2012, p. 411. Disponível em: http://gthistoriacultural.com.br/VIsimposio/ anais/Karlene\%20Sayanne\%

20Ferreira\%20Araujo\%20\&\%20Francisco\%20Alcides\%20do\%20

Nascimento.pdf. Acesso em: 10 jan.2016. 


\begin{tabular}{|c|c|}
\hline $\begin{array}{l}\text { XVII Simpósio Brasileiro } \\
\text { de Geografia Fisica Aplicada }\end{array}$ & $\begin{array}{c}\text { OS DESAFIOS DA GEOGRAFIA FÍSICA NA FRONTEIRA DO CONHECIMENTO } \\
\text { Instituto de Geociências - Unicamp }\end{array}$ \\
\hline $\begin{array}{l}\text { I Congresso Nacional } \\
\text { de Geografia Física }\end{array}$ & $\begin{array}{l}\text { Campinas - SP } \\
28 \text { de Junho à } 02 \text { de Julho de } 2017\end{array}$ \\
\hline
\end{tabular}

